\title{
Bradyarrhythmia development and permanent pacemaker implantation after cardiac surgery
}

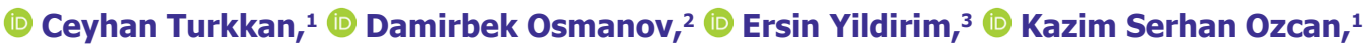 \\ Servet Altay, ${ }^{4}$ (D) Hakan Hasdemir, ${ }^{5}$ (D) Ahmet Taha Alper, ${ }^{1}$ (D) Nazmiye Ozbilgin, ${ }^{1}$ \\ iD Izzet Celal Erdinler, ${ }^{6}$ (D) Kadir Gurkan ${ }^{1}$ \\ ${ }^{1}$ Department of Cardiology, Health Science University Dr. Siyami Ersek Training and Research Hospital, Istanbul, Turkey \\ 2Department of Cardiology, Bicard Clinic, Bishkek, Kyrgyzstan \\ ${ }^{3}$ Department of Cardiology, Umraniye Training and Research Hospital, Istanbul, Turkey \\ ${ }^{4}$ Department of Cardiology, Trakaya University Faculty of Medicine, Edirne, Turkey \\ ${ }^{5}$ Department of Cardiology, Istanbul Atakent Memorial Hospital, Istanbul, Turkey \\ ${ }^{6}$ Department of Cardiology, Istanbul Atasehir Memorial Hospital, Istanbul, Turkey
}

\begin{abstract}
OBJECTIVE: Bradyarrhythmia is one of the complications that may develop after cardiac surgery. Only a few studies have previously dealt with this concern, and in our study, we investigated the factors affecting the development of atrioventricular block or sinus node dysfunction and the requirement of permanent pacemaker following cardiac surgery.

METHODS: A total of 62 patients who developed the atrioventricular (AV) block or sinus node dysfunction and required a permanent pacemaker following cardiac surgery were included in the study. Among these, 31 patients were evaluated prospectively, and the information regarding 31 patients was evaluated retrospectively based on hospital records. Demographic, clinical, and surgical information was recorded. Patients were grouped according to the types of procedures, including the coronary artery bypass graft, valve surgery, congenital heart disease, and combinations of these. Patients were evaluated by standard 12-lead electrocardiogram and transthoracic echocardiography preoperatively. The postoperative development of bradyarrhythmia and requirement of permanent pacemaker were evaluated.
\end{abstract}

RESULTS: The mean age of patients with preoperative conduction abnormality and wide QRS was statistically significantly higher than those without these disorders. The odds ratio for preoperative conduction abnormality risk in patients over 70 years of age was found as 4.429 (95\% confidence interval, 1.40-13.93). There was no gender-related statistically significant difference in terms of left ventricular ejection fraction, left ventricular dilatation, interventricular septum thickness, the time interval from operation to the development of AV block, concomitant diseases, and complication rates.

CONCLUSION: Preoperative conduction abnormality and wide QRS in patients over 70 years of age was determined as a risk factor.

Keywords: Bradyarrhythmia; cardiac surgery; permanent pacemaker.

Cite this article as: Turkkan C, Osmanov D, Yildirim E, Ozcan KS, Altay S, Hasdemir H, et al. Bradyarrhythmia development and permanent pacemaker implantation after cardiac surgery. North Clin Istanb 2018;5(4):288-294.

Several rhythm abnormalities may occur following cardiac surgery. Although the most common arrhythmia is atrial fibrillation, ventricular arrhythmias and conduction abnormalities may also be observed. Reported incidence of sustained ventricular arrhythmias after cardiac surgery ranges from $0.41 \%$ to $1.4 \%$ 
[1]. Persistent postoperative ventricular arrhythmias require aggressive treatment, and if the cause is not reversible, then the patient often needs an implantable cardioverter defibrillator (ICD). Advances in implantable electronic devices in the last 5 decades have been life saving for many patients. There is a slow but constant increase in pacemaker implantation rates, especially in developed countries with aging populations due to increasing life expectancy [2]. Temporary or permanent pacing may also be required in bradyarrhythmias. It has been reported that permanent pacing may be necessary in $0.8 \%-3.4 \%$ of the patients following coronary artery bypass graft (CABG) surgery for sinus node dysfunction or atrioventricular (AV) conduction abnormalities [1]. Permanent pacing may be required in $2 \%-4 \%$ of the patients after the valve surgery due to bradycardia associated with a complete or high-degree AV block. This rate may increase up to $20 \%$ in procedures associated with calcified aortic stenosis or tricuspid valve replacement (TVR) [1]. The sinus node dysfunction is relatively common following orthotopic heart transplantation, and permanent pacemaker implantation may be necessary in about $20 \%$ of the patients [1].

Although sustained ventricular arrhythmias do not occur very commonly, they are associated with a poor short- and long-term prognosis. The hospital mortality rate may reach $50 \%$ in these patients [1]. It is essential to define the risk factors to prevent these highly mortal arrhythmias or for early intervention.

Not many studies have been previously conducted regarding factors determining the development of $\mathrm{AV}$ block or sinus node dysfunction and the necessity of permanent pacemaker following cardiac surgery. We aimed to investigate the risk factors affecting the development of conduction abnormalities or sinus node dysfunction and requirement of permanent pacemaker following cardiac surgery in this study.

\section{MATERIALS AND METHODS}

In our hospital, a tertiary cardiac center, 62 patients developing $\mathrm{AV}$ block or sinus node dysfunction and requiring permanent pacemaker following cardiac surgery were included in the study. A total of 31 patients operated between January 2008 and July 2009 were evaluated prospectively, and information regarding 31 patients operated before January 2008 was evaluated retrospectively based on hospital records. Demographic, clinical, and surgical information was recorded.
Informed consent was obtained from each patient, and the study protocol conforms to the ethical guidelines of the 1975 Declaration of Helsinki, as reflected in an a priori approval by the local ethics committee of Dr. Siyami Ersek Cardiovascular and Thoracic Surgery Training and Research Hospital.

Patients were grouped according to the types of procedures, including $\mathrm{CABG}$, valve surgery, congenital heart disease, and combinations of these. Patients were preoperatively evaluated for the types of conduction abnormality and QRS duration by standard 12-lead electrocardiogram (ECG). Preoperative transthoracic echocardiography was performed using the GE Vivid 3 and 7 devices and $2.5-3.5 \mathrm{MHz}$ transducers. The standard parasternal short and long axis, as well as apical 4and 2-chamber views, were obtained. The left ventricle (LV) end-systolic and end-diastolic diameters, interventricular septum (IVS) thickness, and the presence of diastolic dysfunction were assessed. The measurement of systolic function was presented as the ejection fraction (EF) calculated by biplane Simpson method. Patients were followed-up for the development of bradyarrhythmia requirement of permanent pacemaker.

The Number Cruncher Statistical System 2007 software (NCSS, Kaysville, Utah) and Power Analysis and Sample Size 2008 software (PASS, Kaysville, Utah) were used for the statistical analysis. In addition to descriptive statistical methods (mean, standard deviation), Student's t-test was used to compare quantitative parameters with normal distribution between the groups. A chi-squared test was used to compare qualitative nonparametric variables. The statistical significance level was set at $\mathrm{p}<0.05$.

\section{RESULTS}

The mean age of 62 patients was $58.69 \pm 17.97$ years, and $64.5 \%$ were male. Nineteen patients $(30.6 \%)$ were $\geq 70$ years old. Preoperative conduction abnormality was present in $38.7 \%$ of the patients $(n=24)$. General characteristics of the patients are presented in Table 1.

As far as concomitant diseases are concerned, 17.7\% of the patients $(n=11)$ had diabetes mellitus, $53.2 \%$ $(n=33)$ had hypertension, $6.5 \%(n=4)$ had chronic renal failure, $43.5 \%(n=27)$ had coronary artery disease, and $3.2 \%(n=2)$ had cerebrovascular event. Preoperative existing conduction abnormalities are shown in Table 2 .

Preoperative QRS duration of the patients ranged 


\begin{tabular}{|c|c|c|c|}
\hline & Mean \pm SD & $\mathrm{n}$ & $\%$ \\
\hline Age (years) & $58.69 \pm 17.97$ & & \\
\hline$<70$ & & 43 & 69.4 \\
\hline$\geq 70$ & & 19 & 30.6 \\
\hline \multicolumn{4}{|l|}{ Gender } \\
\hline Female & & 22 & 35.5 \\
\hline Male & & 40 & 64.5 \\
\hline Hospital length of stay (days) & $13.12 \pm 8.88$ & & \\
\hline Preoperative conduction abnormality & & 24 & 38.7 \\
\hline
\end{tabular}

SD: Standard deviation.

from 0.08 to 0.17 seconds (sec), with a mean value of $0.14 \pm 0.15 \mathrm{sec}$. While wide QRS $(\geq 0.12 \mathrm{sec})$ was noted in $29 \%$ of the patients $(n=18), Q R S$ duration was $<0.12$ $\sec$ in $71 \%(\mathrm{n}=44)$.

While $87.1 \%$ of the patients $(n=54)$ did not use heartrate-limiting medications preoperatively, $12.9 \%(n=8)$ did. Among 8 patients using these drugs, 5 were using beta blockers ( 3 metoprolol, 1 carvedilol, and 1 propranolol); 1 was using calcium channel blocker (diltiazem); and 2 were using beta blocker (metoprolol)+digoxin combination. Surgical interventions performed in the patients are summarized in Table 3.

The mean time interval from the operation to the development of the block was 59.38 $262.84(0-324)$ months. Complete block was noted in $69.4 \%$ of the patients $(n=43)$ postoperatively. Block developed perioperatively (during the operation or within postoperative 7 days) in $27.4 \%(n=17)$ and postoperatively (after postoperative 7 days $)$ in $72.6 \%(n=45)$. Postoperative ECG findings are summarized in Table 4.

An epicardial pacemaker was implanted in $6.5 \%$ $(n=4)$, endocardial pacemaker was implanted in $88.7 \%$ $(\mathrm{n}=55)$, and no pacemaker was implanted in $4.8 \%(\mathrm{n}=3)$ of patients. Among pacemakers implanted in 59 patients, $10.2 \%(n=6)$ were single-chamber rate-responsive pacemakers (the VVIR type), and $89.8 \%(n=53)$ were dual-chamber rate-responsive pacemakers (the DDDR type). Distribution of patient characteristics according to preoperatively existing conduction abnormalities is presented in Table 5.

The mean age of patients with preoperative conduction abnormality was significantly higher than those
TABLE2. Preoperative existing conduction abnormalities

\begin{tabular}{lcc} 
& $\mathrm{n}$ & $\%$ \\
\hline LBBB & 5 & 20.8 \\
RBBB & 5 & 20.8 \\
Incomplete LBBB & 3 & 12.5 \\
Incomplete RBBB & 1 & 4.2 \\
Bifascicular & 5 & 20.8 \\
Trifascicular & 3 & 12.5 \\
2 $^{\text {nd }}$ degree AV block & 2 & 8.4 \\
\hline LBBB: Left bundle branch block; RBBB: Right bundle branch block; AV: Atrio- \\
ventricular.
\end{tabular}

TABLE 3. Surgical interventions

\begin{tabular}{lcc} 
& $\mathrm{n}$ & $\%$ \\
\hline CABG & 21 & 33.9 \\
Valve surgery & 25 & 40.3 \\
CABG + valve surgery & 2 & 3.2 \\
Congenital heart disease & 9 & 14.5 \\
Redo CABG & 2 & 3.2 \\
Redo valve surgery & 1 & 1.6 \\
Congenital heart disease + valve surgery & 2 & 3.2 \\
\hline
\end{tabular}

CABG: Coronary artery bypass grafting.

TABLE 4. Postoperative electrocardiographic findings

\begin{tabular}{lcc} 
& $\mathrm{n}$ & $\%$ \\
\hline $2^{\text {nd }}$ degree Type 1 & 2 & 3.2 \\
$2^{\text {nd }}$ degree Type 2 & 2 & 3.2 \\
Complete block & 43 & 69.4 \\
2:1 block & 7 & 11.3 \\
High degree & 3 & 4.8 \\
Sinus node dysfunction & 5 & 8.1
\end{tabular}

without. While conduction abnormality was present in $63.2 \%$ of the patients $\geq 70$ years of age, it was present in only $27.9 \%$ of those younger than 70 years of age. The odds ratio for preoperative conduction abnormality risk in patients over 70 years of age was found as 4.429 
TABLE 5. Distribution of patient characteristics according to preoperatively existing conduction abnormalities

\begin{tabular}{|c|c|c|c|c|c|}
\hline & \multicolumn{4}{|c|}{ Preoperative conduction abnormality } & \multirow[t]{3}{*}{$\mathrm{p}$} \\
\hline & \multicolumn{2}{|c|}{ Yes $(n=24)$} & \multicolumn{2}{|c|}{ No $(n=38)$} & \\
\hline & $\mathrm{n}$ & $\%$ & $\mathrm{n}$ & $\%$ & \\
\hline Age (years) & \multicolumn{2}{|c|}{$67.20 \pm 13.78$} & \multicolumn{2}{|c|}{$53.31 \pm 18.38$} & 0.002 \\
\hline$<70$ & 12 & 27.9 & 31 & 72.1 & \\
\hline$\geq 70$ & 12 & 63.2 & 7 & 36.8 & 0.009 \\
\hline \multicolumn{6}{|c|}{ Pacemaker implant } \\
\hline Epicardial & 0 & 0 & 4 & 10.5 & 0.025 \\
\hline Endocardial & 24 & 100 & 31 & 81.5 & \\
\hline No implant & 0 & 0 & 3 & 8 & \\
\hline \multicolumn{6}{|l|}{ Pacemaker type } \\
\hline DDDR & 21 & 87.5 & 32 & 84.2 & 0.195 \\
\hline VIR & 3 & 12.5 & 3 & 7.9 & \\
\hline No implant & 0 & 0 & 3 & 7.9 & \\
\hline \multicolumn{6}{|l|}{ Gender } \\
\hline Female & 7 & 31.8 & 15 & 68.2 & 0.409 \\
\hline Male & 17 & 42.5 & 23 & 57.5 & \\
\hline \multicolumn{6}{|c|}{ Block development } \\
\hline Periop & 6 & 35.3 & 11 & 64.7 & 0.734 \\
\hline Postop & 18 & 40.0 & 27 & 60.0 & \\
\hline \multicolumn{6}{|l|}{ QRS duration } \\
\hline$<0.12 \mathrm{sec}$ & 6 & 13.6 & 38 & 86.4 & 0.001 \\
\hline$\geq 0.12 \mathrm{sec}$ & 18 & 100.0 & 0 & 0.0 & \\
\hline \multicolumn{6}{|l|}{$\mathrm{EF}$} \\
\hline$<50 \%$ & 7 & 38.9 & 11 & 61.1 & 0.985 \\
\hline$\geq 50 \%$ & 17 & 38.6 & 27 & 61.4 & \\
\hline \multicolumn{6}{|l|}{ LV dilatation } \\
\hline No & 15 & 42.9 & 20 & 57.1 & 0.445 \\
\hline Yes & 9 & 33.3 & 18 & 66.7 & \\
\hline \multicolumn{6}{|l|}{ Thick IVS } \\
\hline No & 11 & 29.7 & 26 & 70.3 & 0.077 \\
\hline Yes & 13 & 52.0 & 12 & 48.0 & \\
\hline
\end{tabular}

EF: Ejection fraction; IVS: interventricular septum; LV: left ventricle; The results are presented as mean \pm standard deviation or number (\%).

(95\% confidence interval, 1.40-13.93). Distribution of concomitant diseases and complications according to preoperative conduction abnormality status is presented in Table 6.

The coronary artery disease rate in patients with preoperative conduction abnormality was significantly high. There was no significant difference between patients with or without preoperative conduction abnormalities in terms of concomitant disease and complication rates.

\section{DISCUSSION}

The exact mechanism of bradyarrhythmias occurring after cardiac surgery is not fully understood. Approximately $0.8 \%$ to $4 \%$ of patients undergoing cardiac surgery require permanent pacemaker due to bradyarrhythmias that develop after the procedure. The pacemaker requirement was noted in $0.8 \%$ of the patients $(25 / 2948)$ after $\mathrm{CABG}, 3.3 \%(30 / 923)$ after valve surgery, and $2.4 \%$ $(11 / 450)$ for congenital heart disease surgery [3-8]. 
TABLE 6. Distribution of concomitant diseases and complications according to preoperative conduction abnormality status

\begin{tabular}{|c|c|c|c|c|c|}
\hline & \multicolumn{4}{|c|}{ Preoperative conduction abnormality } & \multirow[t]{3}{*}{$\mathrm{p}$} \\
\hline & \multicolumn{2}{|c|}{ Yes $(n=24)$} & \multicolumn{2}{|c|}{ No $(n=38)$} & \\
\hline & $\mathrm{n}$ & $\%$ & $\mathrm{n}$ & $\%$ & \\
\hline DM & 3 & 12.5 & 8 & 21.1 & 0.391 \\
\hline HT & 15 & 62.5 & 18 & 47.4 & 0.245 \\
\hline CRF & 2 & 8.3 & 2 & 5.3 & 0.637 \\
\hline CAD & 15 & 62.5 & 12 & 31.6 & 0.017 \\
\hline Complication & 5 & 20.8 & 7 & 18.4 & 0.815 \\
\hline
\end{tabular}

CAD: Coronary artery disease; CRF: Chronic renal failure; DM: Diabetes mellitus; HT: Hypertension.

Risk factors that have been reported in large-scale studies to be associated with the requirement of permanent pacemaker implantation following cardiac surgery include preexisting conduction disturbances, undergoing AVR, age, diuretic use, and cardiopulmonary bypass duration $[9,10]$. The presence of preoperative rhythm and conduction abnormalities is a significant risk factor for the development of persistent block after the operation. Intra or infra-His bundle conduction abnormality has been found by electrophysiological evaluation in approximately $30 \%$ of patients with calcified aortic stenosis $[8$, $11,12]$. In a series of 120 patients who required postoperative permanent pacemaker implantation, it was also found that there were preoperatively existing rhythm and conduction abnormalities on ECG in 104 (87\%) patients [3]. The number of patients with preoperative ECG rhythm and conduction abnormalities was 24 (38.7\%) in our study.

Merin et al. [9] evaluated data regarding 4999 patients undergoing cardiac surgery between 1993 and 2005 and found that $71 \%$ of the patients were men and the mean age was $64 \pm 12$ years. The CABG was performed in 4071 patients (81\%), AVR in 675 (14\%), and mitral valve replacement (MVR) in 968 (18\%). Permanent pacemaker implantation following surgery was required in $1.4 \%$ of the patients $(n=72)$. Pacemaker indication was a complete AV block in $81.9 \%$ of these patients $(\mathrm{n}=59)$. On multivariate analysis, predictors for pacemaker requirement were found as the left bundle branch block (LBBB) and AVR. Raza et al. [10] evaluated 6268 patients undergoing cardiac surgery between 1987 and 2010 and reported that 141 patients (2.2\%) re- quired permanent pacemaker implantation, which were due to the AV block in $55 \%$ and bradycardia in $45 \%$. Age, diuretic use, cardiopulmonary bypass time, and valve surgery were found as independent predictors of permanent pacemaker requirement. Dawkins et al. [13] evaluated potential risk factors associated with the requirement of permanent pacemaker implantation following isolated AVR in 342 patients. They found that preoperative conduction system abnormality was present in $26 \%$ of the patients. They noted postoperative pacemaker requirement in 29 patients ( $8.5 \%)$. The presence of preoperative conduction system abnormality was found as an independent predictor of permanent pacemaker requirement. Limongelli et al. [14] also evaluated risk factors for the requirement of permanent pacemaker implantation following AVR, and multivariate logistic regression analysis revealed that patients with previous aortic regurgitation, myocardial infarction, pulmonary hypertension, and postoperative electrolyte imbalance were at an increased risk for advanced AV block. Haworth et al. [15] also investigated potential predictors of permanent pacing following transcatheter aortic valve implantation and found the QRS morphology and increased annulus size as partial predictors. However, age, the baseline PR interval, and gender were not noted as predictors. Schurr et al. [16] reported that permanent pacemaker implantation was required in $6.6 \%$ of the 3534 patients undergoing AVR and stated that age was not an independent predictor, but that concomitant severe mitral valve insufficiency, $\mathrm{CABG}$, subaortic stenosis, or re-do operations were independent predictors. In a multi-center study, arrhythmias were investigated in 556 adult patients who have undergone corrective surgery during childhood for 
Fallot tetralogy. Among these, 102 patients (18.3\%) had implanted cardiac rhythm devices, with pacemakers in $44(7.9 \%)$ and ICDs in 58 (10.4\%). Primary pacemaker indications were found as sinus node dysfunction in 8 patients (18.2\%), AV block in 29 (65.9\%), and tachycar$\mathrm{dia} /$ bradycardia syndromes in 7 (15.9\%). Moreover, the QRS width was $\geq 180 \mathrm{msec}$ in 10 patients $(37.0 \%)$, left ventricular EF was $<35 \%$ in 4 (14.8\%), and moderate or severe systolic right ventricular dysfunction was present in $14(51.9 \%)$ as primary prevention indications [17]. In a Japanese multi-center study conducted in a similar group of patients, the prevalence of severe arrhythmias was found to be lower compared to those reported in Western countries, and better results may have been associated with the fact that QRS duration was $<120 \mathrm{msec}$ postoperatively in most of the patients (60\%) [18].

Direct surgical damage to the AV node or bundle of His may explain the postoperative conduction abnormalities. Rarely, the sinus node may be traumatized during the cannulation procedure for cardiopulmonary bypass. Moreover, the sinus node or its vascularization may also be damaged during the Mustard and Senning procedures that are performed in transposition cases. Pathological changes include reversible elements such as edema. Repair of membranous ventricular septal defects (VSD) and atrial septal defects, as well as placement of mitral ring or prosthetic valves, may lead to edema of tissues surrounding the AV node and result in transient blocks $[19,20]$.

An advanced age $[8,21]$ and female gender [21] have previously been associated with postoperative development of permanent conduction block and permanent pacemaker implantation. The mean age was 58.69 years in our patient group and the advanced age was found to be the most significant risk factor. There were 22 women $(35.5 \%)$ in our study group, and gender was not found to be a significant risk factor.

We found that the permanent pacemaker requirement was most common following valve surgery (40.3\%) in the adult population, and MVR (19.4\%) was the most frequently associated procedure. According to previous literature, permanent pacemaker requirement was most common following the AVR (17.3\%) and MVR plus TVR (17\%) procedures [3]. Among congenital heart disease operations, the VSD repair $(54.5 \%)$ has been reported as the procedure that is most frequently associated with permanent pacemaker requirement $[8,21]$.

Complete AV block was found to be the most fre- quent indication (69.4\%) for permanent pacemaker implantation following surgery in our patients. In the series by Goldman et al. [8], the mean time interval between surgery and late development of block or sinus node dysfunction were reported as 4.7 years, which was similar to our finding of 5 years.

As endocardial placement of the electrode and DDDR mode are the currently recommended settings for permanent pacemakers, we preferred endocardial placement in $88.7 \%$ of our patients and DDDR mode in $85.5 \%$.

As far as the timing of permanent pacemaker implantation after cardiac surgery is concerned, various opinions exist. Hancock [19] has recommended that permanent pacemaker be implanted if persistent high degree AV block is detected within 3 days after the surgical procedure, whereas Zakhia Doueihi et al. [7] have recommended that a permanent pacemaker be placed on the $10^{\text {th }}$ day of postoperative heart block detection. In the recent American College of Cardiology/American Heart Association/North American Society of Pacing and Electrophysiology (ACC/AHA/NASPE) 2002 guideline, it has been concluded that AV blocks that develop following cardiac surgery have a variable course, and the decision of permanent pacemaker implantation is left to the physician [22]. It has also been mentioned in the guideline that permanent pacemaker is indicated in adults with AV blocks who are not expected to improve and in children and adolescents if the $2^{\text {nd }}$ or $3^{\text {rd }} \mathrm{de}$ gree AV block continues for 7 days or if the AV block is not expected to improve. In the present study, the mean postoperative hospital length of stay was 13 days in patients requiring permanent pacemaker. We believe that it would be better to reduce this period a bit more.

In conclusion, we found that the presence of preoperative conduction abnormality and wide QRS in elderly patients were significant risk factors for the development of block following cardiac surgery. Further large-scale studies are needed to elucidate the exact mechanism of postoperative bradyarrhythmias.

Conflict of Interest: The authors declare no conflict of interest.

Financial Disclosure: The authors declared that this study has received no financial support.

Authorship Contributions: Concept - C.T.; Design - C.T.; Supervision - C.T.; Materials - C.T., E.Y., K.S.O., S.A.; Data collection \&/or processing - C.T., E.Y., K.S.O., S.A.; Analysis and/or interpretation C.T., D.O., K.S.O., S.A, H.H., A.T.A., N.O., I.C.A, K.B.; Writing - C.T.; Critical review - I.C.E. 


\section{REFERENCES}

1. Chung MK. Cardiac surgery: postoperative arrhythmias. Crit Care Med 2000;28:N136-44.

2. Auricchio A, Moccetti T. Electronic cardiac medicine: present and future opportunities. Swiss Med Wkly 2010;140:w13052. [CrossRef]

3. Glikson M, Dearani JA, Hyberger LK, Schaff HV, Hammill SC, Hayes DL. Indications, effectiveness, and long-term dependency in permanent pacing after cardiac surgery. Am J Cardiol 1997;80:1309-13. [CrossRef]

4. Emlein G, Huang SK, Pires LA, Rofino K, Okike ON, Vander Salm TJ. Prolonged bradyarrhythmias after isolated coronary artery bypass graft surgery. Am Heart J 1993;126:1084-90. [CrossRef]

5. Goldman BS, Hill TJ, Weisel RD, Scully HE, Mickleborough LL, Pym J, et al. Permanent cardiac pacing after open-heart surgery: acquired heart disease. Pacing Clin Electrophysiol 1984;7:367-71. [CrossRef]

6. Keefe DL, Griffin JC, Harrison DC, Stinson EB. Atrioventricular conduction abnormalities in patients undergoing isolated aortic or mitral valve replacement. Pacing Clin Electrophysiol 1985;8:393-8. [CrossRef]

7. Zakhia Doueihi R, Leloux MF, De Roy L, Krémer R. Permanent cardiac pacing for prolonged second and third degree atrioventricular blockcomplicating cardiac valve replacement. Acta Cardiol 1992;47:157-66.

8. Goldman BS, Williams WG, Hill T, Hesslein PS, McLaughlin PR, Trusler GA, et al. Permanent cardiac pacing after open heart surgery: congenital heart disease. Pacing Clin Electrophysiol 1985;8:732-9.

9. Merin O, Ilan M, Oren A, Fink D, Deeb M, Bitran D, et al. Permanent pacemaker implantation following cardiac surgery: indications and long-term follow-up. Pacing Clin Electrophysiol 2009;32:7-12.

10. Raza SS, Li JM, John R, Chen LY, Tholakanahalli VN, Mbai M, et al. Long-term mortality and pacing outcomes of patients with permanent pacemaker implantation after cardiac surgery. Pacing Clin Electrophysiol 2011;34:331-8. [CrossRef]

11. Fukuda T, Hawley RL, Edwards JE. Lesions of conduction tissue complicating aortic valvular replacement. Chest 1976;69:605-14. [CrossRef]

12. Friedman HS, Zaman Q, Haft JI, Melendez S. Assessment of atrioventricular conduction in aortic valve disease. Br Heart J 1978;40:911-7.

13. Dawkins S, Hobson AR, Kalra PR, Tang AT, Monro JL, Dawkins
KD. Permanent pacemaker implantation after isolated aortic valve replacement: incidence, indications, and predictors. Ann Thorac Surg 2008;85:108-12. [CrossRef]

14. Limongelli G, Ducceschi V, D’Andrea A, Renzulli A, Sarubbi B, De Feo $\mathrm{M}$, et al. Risk factors for pacemaker implantation following aortic valve replacement: a single centre experience. Heart 2003;89:901-4. [CrossRef]

15. Haworth P, Behan M, Khawaja M, Hutchinson N, de Belder A, Trivedi $U$, et al. Predictors for permanent pacing after transcatheter aortic valve implantation. Catheter Cardiovasc Interv 2010;76:751-6. [CrossRef]

16. Schurr UP, Berli J, Berdajs D, Häusler A, Dzemali O, Emmert M, et al. Incidence and risk factors for pacemaker implantation following aortic valve replacement. Interact Cardiovasc Thorac Surg 2010;11:556-60.

17. Khairy P, Aboulhosn J, Gurvitz MZ, Opotowsky AR, Mongeon FP, Kay J, et al. Arrhythmia burden in adults with surgically repaired tetralogy of Fallot: a multi-institutional study. Circulation 2010;122:86875. [CrossRef]

18. Nakazawa M, Shinohara T, Sasaki A, Echigo S, Kado H, Niwa K, et al; Study Group for Arrhythmias Long-Term After Surgery for Congenital Heart Disease: ALTAS-CHD study. Arrhythmias late after repair of tetralogy of fallot: a Japanese Multicenter Study. Circ J 2004;68:12630. Erratum in:Circ J 2004;68:403. [CrossRef]

19. Hancock EW. AV block after aortic valve replacement. Hosp Pract (Off Ed) 1988;23:41,44,48. [CrossRef]

20. Miller JM, Cossu SF, Josephson ME. Arrhythmias resulting from cardiac surgical procedures. In: Edmunds LH Jr, editors. Cardiac surgery in the adult. New York: Mc Graw-Hill; 1997.p. 731.

21. Del Rizzo DF, Nishimura S, Lau C, Sever J, Goldman BS. Cardiac pacing following surgery for acquired heart disease. J Card Surg 1996;11:332-40. [CrossRef]

22. Gregoratos G, Abrams J, Epstein AE, Freedman RA, Hayes DL, Hlatky MA, et al. ACC/AHA/NASPE 2002 guideline update for implantation of cardiac pacemakers and antiarrhythmia devices: summary article: a report of the American College of Cardiology/American Heart Association Task Force on Practice Guidelines (ACC/AHA/NASPE Committee to Update the 1998 Pacemaker Guidelines). Circulation 2002;106:2145-61. [CrossRef] 